785 SINGLE-CENTER EXPERIENCE WITH LEVOSIMENDAN AS AN ALTERNATIVE TO CATECHOLAMINE IN CHILDREN WITH SEVERE CATECHOLAMINE DEPENDENT END-STAGE HEART FAILURE

doi:10.1136/archdischild-2012-302724.0785

F Alsohime. Louis Pradel Hospital, Lyon, France

Objective To describe our preliminary experience with Levosimendan during the last 4 years, a new calcium-sensitizing agent in critically unwell infants and children with severe heart failure.

Design Retrospective cohort analysis.

Setting Pediatric cardiology intensive care unit.

Patients 8 children aged 2.5 months to 13 yrs (median age 44 months) with severe myocardial dysfunction secondary to endstage heart failure who were inotropedependent (requiring at least one catecholamine).

Interventions A single dose (continuous intravenous infusion over $24 \mathrm{hrs}$ ) of Levosimendan was given under continuous hemodynamic monitoring in our intensive care unit.

Six children received a single dose, two children received two doses,

Echocardiographic assessments of ventricular function were made before and 3-5 days after Levosimendan infusion.

Measurements and Main Results Heart rate, systolic pressure, diastolic pressure, mean blood pressure, shortening fraction, the dose of inotrope at the beginning of levosimendan infusion, at 24 hours and 36 hours, ECG result 24 hour after levosimendan infusion.

Conclusions Levosimendan appeared to be a safe and efficacious drug when given to children with uncompensated end-stage heart failure in this size-limited sample. It warrants formal prospective large-cohort evaluation and multicenter trial to determine its safety profile and clinical application in the pediatric population.

\section{LOW PLATELET COUNT IS ASSOCIATED WITH DUCTUS ARTERIOSUS PATENCY IN PRETERM NEWBORNS}

doi:10.1136/archdischild-2012-302724.0786

E Alyamac Dizdar, R Ozdemir, FN Sari, S Yurttutan, T Gokmen, 0 Erdeve, FE Canpolat, N Uras, SS Oguz, U Dilmen. Neonatal Intensive Care Unit, Zekai Tahir Burak Maternity and Teaching Hospital, Ankara, Turkey

Background and Aims To determine whether there is an association between platelet counts and patent ductus arteriosus (PDA) incidence and/or closure in preterm newborns.

Methods Premature infants with hemodynamically significant PDA $(n=154)$ and a control group without PDA $(n=207)$ who were hospitalized in the NICU were eligible. Platelet counts and other platelet indices including mean platelet volume (MPV) and platelet distribution width (PDW) of the infants in both groups during the first 3 days of life were recorded. Ibuprofen was started in infants with hemodynamically significant PDA and echocardiography was repeated 48 hours thereafter to assess the closure of ductus.

Results Median gestational age and birth weight of the infants with PDA were 28 (range 26-29) weeks and 1060 (range 892-1250) gr respectively. Platelet counts were significantly lower in the patient group than in the control group $(p<0,001)$. Multivariate analysis including gestational age, presence of RDS, presence of thrombocytopenia and PDW showed that platelet count $<150.000$ (OR=2.13, 95\% CI 1.26-3.61; $\mathrm{p}=0.005)$, high PDW $(>17)(\mathrm{OR}=2.68,95 \% \mathrm{CI}$ $1.41-5.09 ; \mathrm{p}=0.003)$ and the presence of $\mathrm{RDS}(\mathrm{OR}=2.25,95 \% \mathrm{CI}$ 1.41-3.59; $\mathrm{p}=0.001$ ) were independently associated with higher risk of hemodynamically significant PDA. Baseline platelet counts of the infants in whom ductus closed or persisted after ibuprofen treatment were similar.

Conclusions Low platelet count was associated with ductus arteriosus patency in preterm infants while other platelet indices were not. We could not show an association between platelet counts and persistence or closure after medical treatment.

\section{WHAT IS THE EFFECT PDA AND ITS MEDICAL CLOSURE ON CEREBRAL AND ABDOMINAL TISSUE OXYGENATION IN PRETERM NEWBORNS?}

doi:10.1136/archdischild-2012-302724.0787

E Ergenekon, I Hirfanoglu, S Beken, N Altuntas, E Kazancı, S Unal, F Kulalı, S Aktas, E Onal, C Turkyılmaz, E Koc, Y Atalay. Pediatrics/Newborn Medicine, Gazi University Hospital, Ankara, Turkey

Background and Aim Patent ductus arteriosus (PDA) is a frequent problem in preterms known to have significant effects on organ perfusion. The aim of this study was to investigate the difference between cerebral and abdominal tissue oxygenation index (TOI) measured by near infrared spectroscopy (NIRS) before and after treatment of hemodynamically significant PDA in preterm newborns.

Methods Cerebral and abdominal TOI were recorded by NIRS (NIRO 200 Hamamatsu, Japan) in preterm newborns with hemodynamically significant PDA requiring ibuprofen treatment. Newborns with congenital anomalies were excluded. 20 minute recordings were obtained before treatment and after documented ductal closure by echocardiography as well as real time oxygen saturation $\left(\mathrm{SaO}_{2}\right)$ monitoring by pulse oxymetry. Fractional tissue oxygen extraction (FTOE) was calculated using $\mathrm{TOI}$ and $\mathrm{SaO}_{2}$.

Results Fourteen newborns were included, abdominal recordings were available in 13. Mean BW and GA were $1089 \mathrm{~g}$ and 29 weeks respectively. No change was observed in cerebral or abdominal tissue oxygenation and oxygen extraction before and after medical closure of PDA. Pre and posttreatment cerebral TOI values (median and range) were 67.17 (50.9-89.1) and 64.35 (54.9-87.4) $\mathrm{P}=0.3$, and pre and posttreatment cerebral FTOE values were $0.3(0.03-0.45)$ and $0.29(0.05-0.42) \mathrm{p}=0.09$ respectively. Pre and postreatment abdominal TOI values were (median and range) 53.9 (40.1-62.9) and 50.29 (39.2-78.5) $\mathrm{P}=0.7$, pre and posttreatment abdominal FTOE values were $0.44(0.32-0.59)$ and $0.46(0.2-0.6) \quad p=0.8$ respectively.

Conclusion Results of this small group may suggest that cerebral and abdominal tissue oxygenation is preserved during hemodynamically significant PDA, however more detailed studies are warranted.

\section{FETAL HYPOXIA-ISCHEMIA IS RELATED TO CIRCULATORY COMPROMISE IN PRETERM INFANTS}

doi:10.1136/archdischild-2012-302724.0788

'DC Vijlbrief, 'MJNL Benders, ${ }^{2} \mathrm{H}$ Kemperman, ' $\mathrm{F}$ van Bel, 'WB de Vries. 'Neonatology; ${ }^{2}$ Clinical Chemistry and Hematology, Wilhelmina Children's Hospital/University Medical Center Utrecht, Utrecht, The Netherlands

Background and Aims Impairment of gas exchange and blood flow through the placenta leads to hypoxia and hypercapnia. This causes increased systemic vascular resistance and tachycardia, thus compromising the cardiovascular system of the foetus. The biomarker B-type natriuretic peptide (BNP) can be used to identify significant cardiovascular compromise in infants. The aim of the present study was to investigate whether BNP can be used to identify those preterm infants with significant cardiovascular compromise during peripartum period.

Methods In this retrospective cohort study all infants born after a gestational age of less than 32 weeks were evaluated. Maternal, fetal and infant factors associated with prenatal and perinatal hypoxiaischemia were related to BNP levels after birth. Pathologic examination of the placenta was routinely performed. 